\title{
Increasing feed efficiency using genetic improvement and intensive pasture based systems of
} milk production

\author{
J Coleman $^{1,2}$, B Horan ${ }^{1}$, K P Pierce ${ }^{2}$, D P Berry ${ }^{1}$ \\ ${ }^{1}$ Teagasc Moorepark Dairy Production Research Centre, Fermoy, Co. Cork, Ireland \\ ${ }^{2}$ University College Dublin, Dublin, Ireland
}

Email:john.coleman@teagasc.ie

Introduction The increased milk production required to meet future global demands will be realised by expansion of dairy herds as well as increased efficiency of milk production both through improvements in management and in genetic merit for feed efficiency. The objective of this study was to investigate the influence of genetic improvement using the Irish total merit index, the economic breeding index (EBI) on feed efficiency within likely future pasture-based production systems under a post EU milk quota scenario.

Materials and methods The study was carried out at Moorepark dairy research centre in the Republic of Ireland over a 2 year period (2007 and 2008). Three genetic groups of Holstein-Friesian (HF) dairy cattle were established from within the Moorepark herd: LowNA, national average EBI North American HF (EBI = €49); HighNA, high EBI North American HF $(\mathrm{EBI}=€ 75)$; HighNZ, high EBI New Zealand HF $(\mathrm{EBI}=€ 88)$. Animals were randomly allocated to one of two intensive pasture-based feed systems (FS): 1) the Moorepark pasture (MP) system; 2.64 cows per ha and $344 \mathrm{~kg}$ concentrates per cow and 2) a high output per hectare (HC) system, 2.85 cows per ha and 1,056 kg concentrates per cow. Milk yield was recorded daily and milk composition was recorded weekly throughout the study. Animal bodyweight (BW) was recorded weekly with animal body condition score (BCS) measured every three weeks. Individual cow dry matter intake (DMI) was estimated on six occasions each year using the n-alkane technique.

Feed conversion efficiency (FCE) was defined as the kg of milk solids (MS) per cow per day divided by the total DMI of that cow on that day

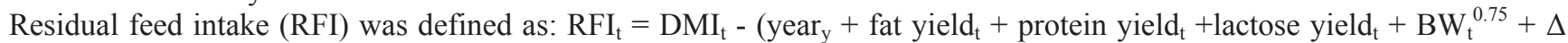
$\mathrm{BW}_{\mathrm{t}}+\mathrm{BCS}_{\mathrm{t}}$,

Residual solids production (RSP) was defined as: $\mathrm{RSP}_{\mathrm{t}}=\mathrm{MS}$ yield $t-\left(\right.$ year $\left._{\mathrm{y}}+\mathrm{TDMI}_{\mathrm{t}}+\mathrm{BW}_{\mathrm{t}}^{0.75}+\Delta \mathrm{BW}_{\mathrm{t}}+\mathrm{BCS}_{\mathrm{t}}\right)$

where $\mathrm{t}=$ day post calving; and $\mathrm{y}=$ year $(1$ or 2$) ; \Delta \mathrm{BW}=$ instantaneous change in $\mathrm{BW}$ at day $\mathrm{t}$ estimated from the first derivative of a lactation profile and fitted in the model as a piecewise regression to account for the different energy requirements for BW gain compared to energy gained from tissue mobilisation.

The effect of genotype and FS on MS production, DMI and feed efficiency were determined using mixed models (Proc Mixed, Statistical Institute, 2006) with cow included as a random effect. Models included the effects of genotype, FS, year, parity, and their interactions.

Results and discussion The effects of genotype and FS on MS production, DMI and efficiency are described in Table 1. The HighNA and HighNZ genotypes produced greater MS yield compared to LowNA animals. The HighNZ animals were lighter but had greater BCS compared to their HighNA and LowNA contemporaries. Animals on the HC FS had greater total DMI across lactation compared to animals on the MP FS. Animals on the HC FS produced greater volumes of MS per day compared to animals on the MP FS.

The ranking of genotypes for feed efficiency was not consistent across the different definitions used. Both HighNA and HighNZ genotypes had superior FCE. However FCE is a poor definition of efficiency in breeding programmes as it is correlated with its component traits and responses to selection can be difficult to predict. The main reason for the inferior RFI of the HighNZ was because they were lighter despite producing more MS than the LowNA with similar intake. The HighNZ animals however had superior RSP. Furthermore, RFI is not correlated with MS production and thus a low (i.e., superior) RFI animal could be low yielding; RSP on the other hand was correlated with MS production implying that superior RSP animals, on averaged, yielded more MS.

Table 1 The effect of genotype and feed system on production, intake, and feed efficiency of spring calving dairy cows.

\begin{tabular}{|c|c|c|c|c|c|c|c|c|c|}
\hline & \multicolumn{3}{|c|}{ Genotype } & \multicolumn{2}{|c|}{ Feed System } & \multirow[t]{2}{*}{ SE } & \multicolumn{3}{|c|}{$P$-value } \\
\hline & LowNA & HighNA & HighNZ & MP & $\mathrm{HC}$ & & $\mathrm{G}^{1}$ & $\mathrm{FS}^{2}$ & G X FS \\
\hline Milk solids $(\mathrm{kg} / \mathrm{d})$ & $1.43^{\mathrm{a}}$ & $1.48^{\mathrm{b}}$ & $1.50^{\mathrm{b}}$ & 1.39 & 1.55 & 0.025 & 0.02 & $<0.001$ & 0.93 \\
\hline Total DMI (kg/d) & 16.6 & 16.6 & 16.5 & 15.9 & 17.2 & 0.22 & 0.76 & $<0.001$ & 0.50 \\
\hline BW (kg) & $531^{\mathrm{a}}$ & $541^{\mathrm{a}}$ & $506^{\mathrm{b}}$ & 525 & 527 & 6.8 & $<0.001$ & 0.79 & 0.27 \\
\hline BCS (units) & $2.75^{\mathrm{a}}$ & $2.82^{\mathrm{ab}}$ & $2.91^{\mathrm{b}}$ & 2.79 & 2.86 & 0.030 & $<0.001$ & 0.02 & 0.73 \\
\hline FCE (g/kg) & $87^{\mathrm{a}}$ & $90^{\mathrm{b}}$ & $91^{\mathrm{b}}$ & 87 & 91 & 1.2 & $<0.001$ & 0.004 & 0.32 \\
\hline RFI (kg DM/d) & $0.14^{\mathrm{a}}$ & $-0.23^{b}$ & $0.21^{\mathrm{a}}$ & -0.10 & 0.53 & 0.124 & $<0.001$ & 0.012 & 0.35 \\
\hline $\operatorname{RSP}(\mathrm{kg} / \mathrm{d})$ & $-0.04^{\mathrm{a}}$ & $0.02^{\mathrm{b}}$ & $0.02^{b}$ & -0.03 & 0.03 & 0.017 & 0.001 & 0.004 & 0.27 \\
\hline
\end{tabular}

${ }^{\mathrm{a}-\mathrm{b}}$ Means within a row with different superscripts differ $(P<0.05)$.

Conclusions The results suggest that genetic selection using EBI can significantly increase MS production through improved feed efficiency. The results show that while a number of definitions of feed efficiency exist, conventional definitions such as FCE and RFI may be inappropriate. Residual solids production is an alternative definition of feed efficiency that identifies increased MS production for a given feed intake. However, further genetic analysis needs to be undertaken to determine its association with other traits. 